\title{
A indústria da carne em Rondônia como paradigma neoextrativista de desenvolvimento
}

\section{The beef industry in Rondônia as a neoextracivist development paradigm}

Charles Carminati de Lima - Doutor em Desenvolvimento Regional pela Universidade Regional de Blumenau (FURB) em Santa Catarina. Professor da Fundação Universidade Federal de Rondônia (UNIR). E-mail: charles@unir.br

Luciano Félix Florit - Doutor em Sociologia pela Universidade Federal do Rio Grande do Sul (UFRGS). Professor da Universidade Regional de Blumenau (FURB). E-mail: lucianoflorit@gmail.com

\section{Resumo}

Este artigo remete ao debate crítico sobre o neoextrativismo e fundamenta a importância da reflexão normativa em torno dos padrões de desenvolvimento, sendo muitas vezes decorrentes de fatores condicionados pelas relações de poder que se consolidam como modelo econômico predominante no território. Este estudo contribui no sentido de ampliar a concepção do neoextrativismo também para a atividade pecuária em Rondônia, principalmente após a implementação na década de 1970 de políticas que estimularam o crescimento da indústria da carne, cuja exploração envolve grandes investimentos de infraestrutura e que geram alta concentração de renda. No caso de Rondônia, atividades econômicas como a pecuária e a produção de grãos são legitimadas ao ponto de justificar uma suposta "vocação" regional do estado para o agronegócio. Pelo estudo realizado entre os anos de 2000 e 2019 na indústria da carne em Rondônia, é possível afirmar que essas atividades impactam na formulação de políticas concentradoras de recurso, e pouco equitativas na distribuição da renda, pois geram poucos empregos diretos e com baixa remuneração.

\section{Palavras-chave}

Neoextrativismo. Indústria da carne. Desenvolvimento regional. Rondônia.

\begin{abstract}
This article refers to the critical debate on neoextractivism and underlies the importance of normative reflection on development patterns, which are often the result of factors conditioned by power relations that are consolidated as the predominant economic model in the territory. This study contributes towards broadening the concept of neoextractivism also for livestock activities in Rondônia, especially after the implementation in the 1970s of policies that stimulated the growth of the meat industry, whose exploration involves large investments in infrastructure and which generate high concentration of income. In the case of Rondônia, economic activities such as livestock and grain production are legitimized to the point of justifying a supposed regional vocation of the state for agribusiness. According to the study carried out between 2000 and 2019 in the meat industry in Rondônia, it is possible to affirm that these activities impact the formulation of resource-concentrating policies, and are not very equitable in the distribution of income, as they generate few direct and low-paid jobs.
\end{abstract}

\section{Keywords}

Neoextractivism. Beef industry. Regional development. Rondonia. 


\section{INTRODUÇÃO}

Neoextrativismo é um modelo econômico caracterizado pela exploração dos recursos naturais por atividades que envolvem grandes investimentos de infraestrutura e geram alta concentração de renda associada a impactos socioambientais graves. Normalmente, as atividades que são consideradas pela literatura como neoextrativistas são as de extração mineral e as monoculturas de grãos. Este artigo, por sua vez, contribui no sentido de ampliar a concepção do neoextrativismo também para a atividade pecuária em Rondônia, principalmente após a implementação na década de 1970 de políticas de concessão de terras que estimularam grandes empreendimentos econômicos voltados à indústria da carne na Amazônia brasileira.

No modelo neoextrativista, as políticas pautadas na exploração primária dos recursos ambientais não conseguem correlacionar de modo consistente o desenvolvimento com a questão das externalidades ambientais negativas resultantes de sua exploração. No caso de Rondônia, sua dinâmica socioeconômica padronizou o uso e a apropriação da terra para a exploração de atividades complexas como a pecuária e a produção de grãos, que, juntas, resultaram em um conjunto de atividades econômicas que são legitimadas ao ponto de justificar uma suposta "vocação" regional do estado para o agronegócio.

O objetivo deste artigo é problematizar, a partir do paradigma do neoextrativismo, a importância da reflexão normativa em torno dos padrões de desenvolvimento, que são muitas vezes decorrentes de fatores econômicos condicionados pelas relações de poder e se consolidam como um modelo predominante de desenvolvimento no território.

No caso na indústria da carne em Rondônia, é possível afirmar que a atividade integra um processo de reprimarização da economia nacional e internacional que impacta na formulação de políticas de desenvolvimento concentradoras de recurso, com baixa remuneração e pouca geração de empregos diretos.

O percurso teórico e metodológico deste estudo exigiu a compreensão dos principais conceitos sobre desenvolvimento e da formação socioeconômica da indústria pecuária brasileira. Os dados pesquisados entre os anos de 2000 e 2019 envolveram informações demográficas do Brasil e de Rondônia retirados do Instituto Brasileiro de Geografia e Estatística (IBGE), além do levantamento sobre a produção, abate, empregos e remuneração gerados pela indústria frigorífica rondoniense.

Asinformações sobre aproduçãobovina sãodoSistemaIBGEdeRecuperação Automática (SIDRA) e da Agência de Defesa Sanitária Agrosilvopastoril do Estado 
de Rondônia (IDARON). As informações sobre empregos e renda foram extraídas da Relação Anual de Informações Sociais do Ministério da Economia (RAIS/ $\mathrm{ME}$ ). Este trabalho de pesquisa contou com o apoio do Conselho Nacional de Desenvolvimento Científico e Tecnológico (CNPq), da Fundação de Amparo à Pesquisa e Inovação do Estado de Santa Catarina (FAPESC) e da Associação Catarinense das Fundações Educacionais (ACAFE).

\section{O NEOEXTRATIVISMO EM RONDÔNIA COMO PARADIGMA DE DESENVOLVIMENTO}

Embora possua diferentes significados, o conceito de desenvolvimento constitui uma inesgotável fonte de discussão (THEOFANIDES, 1988). Para Mathur (1989), o termo desenvolvimento se refere quase sempre a possibilidades de mudanças sociais. Contudo, esse conceito só se expandiu no século XX, pois, anteriormente, a concepção otimista das coisas era tratada como progresso (FURTADO, 2005).

$\mathrm{O}$ fato de o conceito de desenvolvimento ter assumido um estilo fundamentalmente econômico é comprovado pela concentração atribuída à acumulação de riquezas desde os séculos XVIII e XIX, em consequência da economia clássica burguesa (HEIN, 1981). Posteriormente, o debate sobre desenvolvimento passou a considerar como foco principal o crescimento da renda per capita, reduzindo a discussão apenas ao crescimento econômico (FURTADO, 2005).

O foco na acumulação de capital foi outra característica histórica que marcou a discussão sobre o conceito de desenvolvimento. A discussão está apoiada nas contribuições de Karl Marx, que analisou o conceito a partir da problemática sobre o modo de acumulação capitalista de produção (THEIS, 2008).

Por outro lado, a discussão sobre desenvolvimento considera com grande relevância o papel dos indicadores, que geralmente possuem objetivo de evidenciar e mensurar o nível de desenvolvimento de uma região ou país, que muitas vezes não leva em conta os custos da acumulação sobre os valores culturais e da qualidade ambiental (GOULET, 1992).

De acordo com Furtado (2005), desde que o desenvolvimento começou a ser medido, estabeleceu-se um grau de competição que considera como padrão aceitável os países líderes no processo de acumulação, e são considerados pelos indicadores como desenvolvidos apenas por sua contribuição per capita. A partir desta lógica econômica justificou-se a utilização desses indicadores, apesar de serem considerados indiscutivelmente complexos (ALTVATER, 1992; GOULET, 1992). 
Contudo, os indicadores não podem ser responsabilizados pelos países que apresentam graus de desenvolvimento diferentes. Necessita-se, então, de uma análise de dimensões e características mais qualitativas que não levem em conta apenas a acumulação de capital (THEIS, 2008).

Para Lang (2016), do ponto de vista econômico, opor-se ao desenvolvimento como padrão econômico é visto como um absurdo, algo sem sentido, um erro. No entanto, existem inúmeras razões para desfazer-se do conceito convencional de desenvolvimento sustentado pelas economias que são supostamente "doadoras" de tecnologias com objetivo de auxiliar os países mais pobres, quando, na verdade, o objetivo é gerar renda em seus próprios países.

Outro fato importante no debate sobre o desenvolvimento diz respeito às características naturais associadas às condições sociais no espaço geográfico, que, para Theis (2008), estão relacionadas às conexões entre sociedade e meio ambiente. Essa relação é esclarecida por Peet (1991) a partir da crítica sobre a tese do determinismo geográfico, que tem sua origem no campo da geografia econômica e parte do pressuposto da ação humana ser influenciada pelo meio natural.

No Brasil, desde a década de 1970, não se pode afirmar que sempre existe relação entre o crescimento do PIB e, consequentemente, o bem-estar da população, sendo, portanto, processos distintos (FURTADO, 2005; LANG, 2016). Neste sentido, o processo histórico de migração populacional na Amazônia definiu o modo de produção do espaço regional e o sistema de povoamento urbano (KAMPEL; CÂMARA; MONTEIRO, 2001).

No início da década de 1970, o governo brasileiro adotou uma política de ocupação e colonização que tinha por finalidade não apenas integrar a região, mas também expandir a fronteira agrícola e pecuária do país por meio da concentração populacional em territórios geograficamente reorganizados, principalmente em estados como o Pará, Amazonas, Acre e Rondônia (COSTA SILVA, 2014; COSTA SILVA; CONCEIÇÃO, 2017; MELLO, 2006; TEIXEIRA; FONSECA, 2001).

Particularmente em Rondônia, os projetos de colonização foram implantados nas décadas de 1970 e 1980 por meio da substituição de grandes áreas de seringais nativos para um contexto fundiário, alterando a estrutura de posse e uso da terra, inserindo Rondônia, dentro do sistema produtivo nacional com grande incentivo para a criação de pecuária (OLIVEIRA, 2012).

Foram realizadas obras de infraestrutura - como a pavimentação da BR364, no trecho Cuiabá-Porto Velho - financiadas por recursos do Banco Mundial e amplamente denunciadas por organizações e movimentos ambientalistas internacionais. Tais fatos foram consequências do planejamento das políticas governamentais que incentivaram o crescimento econômico e que acentuaram 
um grande fluxo migratório para o estado (COSTA SILVA, 2014; COSTA SILVA; CONCEIÇÃO, 2017; PAULA; SILVA, 2008).

A expansão das atividades rurais em Rondônia desenvolveu particularidades no espaço agrário que configurou padrões econômicos para a formação do agronegócio. Por efeito, ocasionou a exploração corporativa de grandes empresas do capital globalizado e estabeleceu relações subordinadas ao mercado econômico internacional para a exploração primária de atividades como a pecuária e as monoculturas (COSTA SILVA, 2014).

Igualmente, na região latino-americana, com forte apoio do Estado, o sistema de produção rural se apresenta como o carro-chefe do desenvolvimento econômico regional. A apropriação de áreas para o agronegócio passou a ser considerado como um ativo do capital nacional e estrangeiro, que produz a expropriação do campesinato em suas formas coletivas de produção agrícola, amplia a degradação ambiental e estimula os conflitos agrários (FERNANDES, 2008).

Desse processo, traduzem-se resultados econômicos em escala global e consequências socioambientais em escala regional. Da mesma forma, são evidentes os investimentos empresariais e os incentivos governamentais por meio de políticas voltadas para o crescimento dessas atividades. Esse modelo econômico e político, de incentivo às indústrias primário-exportadoras de base extrativa, vem sendo tratado pela literatura como neoextrativismo (ACOSTA, 2016; GUDYNAS, 2009; SVAMPA, 2016).

O neoextrativismo é definido como um modelo de desenvolvimento econômico focado na exploração de recursos naturais, em redes produtivas pouco diversificadas e abarca passivos ambientais devido à impossibilidade da regeneração desses recursos (MILANEZ; SANTOS, 2013; SCOTTO, 2011).

Para Gudynas (2009), a contribuição dos setores extrativistas continua sendo um pilar importante para os estilos de desenvolvimento adotados na gestão dos governos latino-americanos, que embora promovam "um novo extrativismo", não se observam mudanças substantivas em sua atual estrutura de acumulação econômica. Essa conclusão é corroborada por Scotto (2011) ao afirmar que a dependência da extração dos recursos naturais como vetor de crescimento econômico não é uma novidade na América Latina, pois tem sido praticada desde o período colonial.

O conceito de neoextrativismo corresponde a uma reconfiguração do extrativismo tradicional. Foi construído para definir um conjunto de ações vinculadas a setores econômicos que extraem um grande volume de recursos naturais. O conceito normalmente se refere a atividades de exploração dos 
recursos minerais e de petróleo; podendo também ser associado a atividades agrárias (ACOSTA, 2016; GUDYNAS, 2012a, 2012b).

No entanto, não se tem observado um caminho aberto para uma discussão de redistribuição das receitas e dos bens patrimoniais oriundos desta exploração. Para Acosta (2016), essa situação se explica pelo fato de ser relativamente fácil obter vantagem da natureza sem precisar entrar na discussão dos impactos e dos custos ambientais do processo extrativo. Pouco se questiona o papel das indústrias extrativas. Ao contrário, busca-se criar argumentos para justificar sua adoção, a exemplo da justificativa que essas atividades são importantes para o crescimento econômico regional (GUDYNAS, 2012b).

Outro argumento defendido é que as atividades extrativas são vistas como fontes de riqueza e auxiliam na geração de empregos e no combate à pobreza, impulsionando, dessa forma, o apoio de sindicatos e outros movimentos sociais para o aumento da extração dos recursos naturais. Nesse sentido, uma variação do discurso do crescimento econômico em escala local diz respeito às indústrias extrativas como vetores de desenvolvimento (GUDYNAS, 2012a).

No Brasil, o debate sobre neoextrativismo é recente e a população dificilmente percebe o país como aquele que possui atividades predominantemente de base extrativa. No contexto econômico brasileiro, a presença do neoextrativismo pode ser entendida pelo processo de reprimarização ${ }^{1}$ da economia, medido pela participação da indústria extrativa no Produto Interno Bruto (PIB) e pela exportação de bens primários, como os agrícolas e minerais (BARTON, 2006; MILANEZ; SANTOS, 2013).

Por outro lado, apesar do alto resultado econômico na balança comercial, grande parte dos graves problemas causados pelas atividades de concepção neoextrativista diz respeito aos elevados custos econômicos dos impactos socioambientais gerados por sua exploração. De acordo com Acosta (2016), se estes fossem contabilizados, grande parte de seus benefícios econômicos e sociais desapareceriam.

Embora o debate sobre o neoextrativismo esteja concentrado nas atividades da indústria mineral e agrícola (ACOSTA, 2016; GUDYNAS, 2012b; MILANEZ; SANTOS, 2013), seus sinais também são percebidos por meio da criação pecuária e pela indústria da carne, pois essas atividades apresentam características similares, a exemplo das diferentes vantagens e externalidades ambientais negativas que resultam nas diferentes escalas territoriais (ACOSTA, 2016; LIMA, 2019).

\footnotetext{
Conceito derivado da economia, relacionado à desindustrialização. Isto é, maior valorização dos produtos primários, minerais e agrícolas.
} 
Com efeito, o desenvolvimento do sistema de produção rural se expressa na Amazônia brasileira na relação econômica dirigida por capitais industriais e financeiros, que avança com fortes impactos em regiões do Mato Grosso, bem como no sudeste do Pará, no norte do Tocantins e no sul de Rondônia (COSTA SILVA, 2014). Da mesma forma, a pecuária extensiva em Rondônia também possui categorias similares a essas, pois necessita de grandes extensões territoriais para a sua produção, o que produz impactos socioambientais diversificados. Ademais, sua relação econômica está associada a capitais industriais subordinados ao mercado econômico internacional (LIMA, 2019).

O Brasil possui um dos maiores rebanhos bovinos do mundo, e assim como a soja, a pecuária possui proeminência mundial na produção de carne para exportação, sendo a atividade que ocupa a maior extensão territorial do país (SCHLESINGER, 2010). Setores industriais como o grupo JBS-Friboi têm recebido a concessão de empréstimos governamentais, a exemplo do Banco Nacional de Desenvolvimento Econômico e Social (BNDES) (GUDYNAS, 2012a).

Outra similaridade da atividade pecuária com o modelo neoextrativista diz respeito ao grande apoio estatal para o movimento de internacionalização do setor nas últimas décadas. De acordo com Schlesinger (2010), metade do mercado mundial de carne bovina pertence a empresas frigoríficas brasileiras, como a JBS-Friboi e a Marfrig Global Foods, que receberam apoio governamental por meio do BNDES.

As externalidades ambientais negativas constituem outra característica comum às empresas que integram o modelo econômico neoextrativista em Rondônia. A pecuária, juntamente com as atividades agrícolas e madeireiras, é apontada como um dos principais vetores de expansão da fronteira agrícola, além de impactar de maneira significativa os ecossistemas, degradar o solo, poluir os recursos hídricos e contribuir com o aumento da emissão de gases do efeito estufa (ZEN et al., 2008).

Do ponto de vista social e econômico, as relações de apropriação da natureza são construídas e naturalizadas historicamente, sendo assim legitimadas (GUDYNAS, 1999, 2012b). Da mesma forma, nas atividades da pecuária e da indústria da carne, as relações mercantis são legitimadas como supostas "vocações regionais" e a produção e a comercialização dos produtos de origem animal são estabelecidas economicamente tanto em escala nacional quanto internacional (FLORIT; GRAVA, 2016; GRAVA, 2019).

Essas supostas vocações se fortalecem nas relações sociais e políticas vinculadas aos grandes grupos econômicos e aos setores governamentais e, desta forma, tendem a desconsiderar quaisquer outras possibilidades produtivas no território (FLORIT; GRAVA, 2016). 


\section{ANÁLISE SOCIOECONÔMICA DA INDÚSTRIA PECUÁRIA EM RONDÔNIA}

O crescimento da indústria da carne em Rondônia depende de padrões de consumo que não se apoiam na escala geográfica local nem regional, mas em padrões definidos em escala global, situados especialmente na Europa e nos Estados Unidos (COSTA SILVA, 2014). Por outro lado, com base na estimativa de demandas nos próximos anos, Heinrich Böll Foundation (2016) afirma que, do total do crescimento econômico previsto até 2022, até $80 \%$ poderá ser referente à produção de carne para os mercados consumidores da China e Índia.

O setor de produção de carne está concentrado em organizações empresariais que estão se expandindo para além das fronteiras e diversificando as espécies de animais para o abate. A empresa brasileira $\mathrm{JBS}^{2}$ possui capacidade de abate de 85 mil cabeças de gado bovino, 70 mil porcos e 12 milhões de aves diariamente, e fez com que o Brasil liderasse o mercado mundial de carnes (HEINRICH BÖLL FOUNDATION, 2016).

Estimulado por políticas nacionais e internacionais de produção de carne, o estado de Rondônia tornou-se uma das principais fronteiras agrícolas do país e uma das regiões mais produtivas do norte brasileiro (Tabela 1). Economicamente, Rondônia se destaca pela produção da pecuária, seguida pelo cultivo de grãos em uma região com extensão territorial menor que os estados do Amazonas e Pará (IBGE, 2019a; MARTINI; MOREIRA; DALLA-NORA, 2015).

Tabela 1 - Rebanho bovino e bubalino no Brasil, Região Norte e Rondônia (2000-2019)

\begin{tabular}{c|c|c|c|c|c|c|c}
\hline ANO & BRASIL & $\mathbf{\%}$ & $\begin{array}{c}\text { REGIÃO } \\
\text { NORTE }\end{array}$ & $\begin{array}{c}\text { \% } \\
\text { Brasil }\end{array}$ & RONDÔNIA & $\begin{array}{c}\% \\
\text { Brasil }\end{array}$ & $\begin{array}{c}\% \\
\text { Norte }\end{array}$ \\
\hline $\mathbf{2 0 0 0}$ & 169.875 .524 & 100 & 24.517 .612 & 14,43 & 5.664 .320 & 3,33 & 23,10 \\
\hline $\mathbf{2 0 0 5}$ & 207.156 .696 & 100 & 41.489 .002 & 20,03 & 11.349 .452 & 5,48 & 27,36 \\
\hline $\mathbf{2 0 1 0}$ & 209.541 .109 & 100 & 42.100 .695 & 20,09 & 11.842 .073 & 5,65 & 28,13 \\
\hline $\mathbf{2 0 1 5}$ & 216.590 .996 & 100 & 49.455 .342 & 22,83 & 13.404 .354 & 6,19 & 27,10 \\
\hline $\mathbf{2 0 1 7}$ & 216.378 .746 & 100 & 49.419 .229 & 22,84 & 14.098 .118 & 6,52 & 28,53 \\
\hline $\mathbf{2 0 1 8}$ & 214.913 .122 & 100 & 49.537 .084 & 23,05 & 14.374 .043 & 6,69 & 29,02 \\
\hline $\mathbf{2 0 1 9}$ & 216.327 .941 & 100 & 50.562 .033 & 23,37 & 14.355 .955 & 6,64 & 28,38 \\
\hline
\end{tabular}

Fonte: dados sistematizados pelos autores com base em IBGE (2019a) e IDARON (2019).

2 A JBS S.A. é uma empresa brasileira fundada em 1953. É o maior frigorífico do setor de carne bovina do mundo. A companhia opera no processamento de carnes bovina, suína, ovina e de frango e no processamento de couros. 
Em termos de números (de cabeças), o rebanho bovino e bubalino no Brasil cresceu 26,50\% em 19 anos (2000 a 2019). Na região Norte, o crescimento correspondeu a 106,00\% no mesmo período. Em Rondônia, houve uma expansão de $153,00 \%$ do rebanho, uma proporção muito acima da pecuária nacional. Em 2019 ela correspondeu a 28,38\% da pecuária da região Norte e a 6,64\% do total da produção nacional.

Outra análise importante que caracteriza Rondônia como uma região de "vocação regional" para a produção de carne diz respeito às microrregiões do estado com maior concentração per capita de bovinos e bubalinos em relação à população local. Para Grava (2019), as “vocações regionais" de um território muitas vezes são estabelecidas de acordo com os interesses predominantes de uma atividade econômica em detrimento de outra, sob pena de perder sua viabilidade econômica.

O conceito de "vocação", para Weber (2004), tem uma conotação religiosa, como "uma missão dada por Deus" (WEBER, 2004, p. 71). A palavra tem origem na tradução da bíblia e logo teria assumido o significado atual "[...] na língua profana de todos os povos protestantes [...]” (WEBER, 2004, p. 72) e da sociedade ocidental de modo geral, como " [...] a valorização do cumprimento do dever no seio das profissões mundanas como o mais excelso conteúdo que a autorrealização moral é capaz de assumir" (WEBER, 2004, p. 72). A noção de "vocação regional" opera, assim, como formulação ideológica que busca legitimar certas atividades como sendo as únicas possíveis para o desenvolvimento genuíno de uma região.

Assim, o modelo econômico da pecuária não revela as condições sociais e políticas de construção da chamada vocação, que é, essencialmente, resultado das interações entre pessoas e o contexto social (FLORIT; GRAVA, 2016). Também chamadas de "especializações", ou ainda de "polos econômicos", as "vocações regionais" se referem ao predomínio de uma ou outra atividade determinada por características próprias de um território, sejam elas "naturais" ou "culturais", o que resultam na sua suposta "vocação" (GRAVA, 2019).

Uma forma de verificar a preeminência da suposta vocação pecuarista é por meio do cálculo per capita das cabeças de animais relativas à população humana que habitam o mesmo território (Tabela 2). O cálculo foi baseado nas informações fornecidas em 2019 pela Agência de Defesa Sanitária Agrosilvopastoril do Estado de Rondônia (IDARON/RO) e confrontadas com o Censo demográfico de 2010. 
Tabela 2 - Produção bovina e bubalina per capita nas microrregiões de Rondônia (2019)

\begin{tabular}{l|c|c|c|c}
\hline $\begin{array}{c}\text { Microrregiões produtoras de } \\
\text { bovinos em Rondônia }\end{array}$ & $\begin{array}{c}\text { Total de } \\
\text { cabeças } \\
\text { em 2019 }\end{array}$ & $\begin{array}{c}\text { População por } \\
\text { microrregião } \\
\text { de Rondônia }\end{array}$ & $\begin{array}{c}\text { \% da } \\
\text { população }\end{array}$ & $\begin{array}{c}\text { Concentração } \\
\text { de cabeças per } \\
\text { capita }\end{array}$ \\
\hline Regional de Porto Velho & 2.340 .774 & 520.974 & 33,35 & 4,49 \\
\hline Regional de Ariquemes & 2.654 .421 & 191.533 & $\mathbf{1 2 , 2 6}$ & $\mathbf{1 3 , 8 6}$ \\
\hline Regional de Ji-Paraná & 2.062 .911 & 239.153 & 15,31 & 8,63 \\
\hline Regional de Jaru & 1.608 .793 & 113.685 & $\mathbf{7 , 2 8}$ & $\mathbf{1 4 , 1 5}$ \\
\hline Regional de Cacoal & 1.624 .449 & 165.829 & 10,61 & 9,80 \\
\hline Regional de Rolim de Moura & 1.527 .096 & 130.431 & $\mathbf{8 , 3 5}$ & $\mathbf{1 1 , 7 1}$ \\
\hline Regional de São Francisco & 1.154 .246 & 63.170 & $\mathbf{4 , 0 4}$ & $\mathbf{1 8 , 2 7}$ \\
\hline Regional de Vilhena & 1.383 .265 & 137.534 & $\mathbf{8 , 8 0}$ & $\mathbf{1 0 , 0 6}$ \\
\hline \multicolumn{1}{c}{ Total de Rondônia } & $\mathbf{1 4 . 3 5 5 . 9 5 5}$ & $\mathbf{1 . 5 6 2 . 3 0 9}$ & $\mathbf{1 0 0}$ & $\mathbf{9 , 1 9}$ \\
\hline
\end{tabular}

Fonte: dados sistematizados pelos autores com base em IBGE (2010) e IDARON (2019).

O total da produção bovina em Rondônia foi de 14.355.955 (milhões) de cabeças em 2019, uma proporção superior a nove vezes a quantidade populacional humana do estado. Pela análise é possível destacar que, das oito microrregiões do estado, cinco possuem o índice de concentração per capita de bovinos acima do percentual populacional: 1) São Francisco (18,27\%), 2) Jaru (14,15\%), 3) Ariquemes (13,86\%), 4) Rolim de Moura (11,71\%) e 5) Vilhena (10,06\%). A regional de São Francisco é a menor região populacional de Rondônia, com isso, a proporção de produção bovina acentua-se superior a quatro vezes em relação à população local.

\section{A INDÚSTRIA PECUÁRIA EM RONDÔNIA E A GERAÇÃo DE EMPREGOS E SALÁRIOS}

A trajetória do desenvolvimento econômico em Rondônia sempre esteve pautada na legitimação da atividade pecuária, inclusive pela justificativa de sua contribuição na balança comercial e na geração de empregos atribuídas ao setor (LIMA, 2019). Contudo, de acordo com Grava (2019), no Brasil, ainda que pese a relevância econômica da atividade pecuária para a balança comercial, em termos socioeconômicos de geração de empregos, não se pode afirmar que o setor seja um grande empregador.

De acordo com os dados da Relação Anual de Informações Sociais (RAIS) correspondentes aos vínculos de empregos diretos (formais) gerados em 
2018, tanto no Brasil como em Rondônia, dos oito setores apresentados pela RAIS, o setor "agropecuária" é um dos que menos emprega, conforme evidenciado na Tabela 3:

Tabela 3 - Quantitativos de empregos por atividade econômica (Brasil e Rondônia, 2018)

\begin{tabular}{|c|c|c|c|c|}
\hline \multirow{2}{*}{ ATIVIDADES ECONÔMICAS } & \multicolumn{2}{|c|}{ BRASIL } & \multicolumn{2}{|c|}{ RONDÔNIA } \\
\hline & Empregos & $\%$ & Empregos & $\%$ \\
\hline Administração Pública & 8.826 .040 & 19,1 & 114.986 & 33,32 \\
\hline Comércio & 9.264 .904 & 20,1 & 82.733 & 23,97 \\
\hline Serviços & 16.708 .852 & 36,2 & 83.034 & 24,06 \\
\hline Indústria de transformação & 7.148 .013 & 15,5 & 35.929 & 10,41 \\
\hline Agropecuária, extração vegetal, caça e pesca ${ }^{3}$ & 1.476 .219 & 4,3 & 13.551 & 3,93 \\
\hline Construção civil & 1.985 .404 & 5,0 & 9.588 & 2,78 \\
\hline Serviços industriais de utilidade pública & 429.435 & 0,9 & 4.016 & 1,16 \\
\hline Extrativa mineral & 221.331 & 0,4 & 1.298 & 0,380 \\
\hline Total & 46.060 .198 & 100 & 345.135 & 100 \\
\hline
\end{tabular}

Fonte: dados sistematizados pelos autores com base em RAIS (2018).

Dos oito segmentos econômicos classificados pelas RAIS, o setor agropecuária, extração vegetal, caça e pesca correspondeu apenas a 4,3\% dos empregos diretos gerados no Brasil e a 3,93\% em Rondônia. Contudo, os dados referentes a esse setor econômico concernem apenas aos vínculos de empregos formais gerados pelas atividades relacionadas à criação animal e a produção agrícola e extrativa. É importante destacar que existe uma proporção de empregos ligados a este segmento que não são considerados formais e, desta forma, não são registrados pelos vínculos de empregos do Ministério da Economia (ME).

Portanto, para uma análise mais detalhada da participação dos setores ligados à indústria pecuária no total de vínculos de empregos gerados nas microrregiões de Rondônia, foram sistematizados, conforme a Classificação Nacional de Atividade Econômicas (CNAE), os dois setores que abrangem toda a atividade de criação, abate e transformação dos produtos derivados da carne. São eles: a) setor de pecuária ${ }^{4}$ e b) setor de abate e fabricação de produtos de carne ${ }^{5}$. A partir dos dados da RAIS (2018), esses dois setores juntos foram

3 Esse setor compreende apenas as atividades relacionadas à criação animal, produção agrícola e produção extrativa.

4 Compreende a criação de bovinos, ovinos, caprinos, bufalinos para corte e leite, e a criação de equinos e suínos.

5 Compreende o abate em matadouros e frigoríficos. A produção de carne verde, congelada e frigorificada de bovinos, ovinos, caprinos, bufalinos e equídeos, em carcaças ou em peças. A 
responsáveis pela geração de apenas 6,34\% dos empregos totais (diretos) em Rondônia, conforme demonstrado na Tabela 4.

Em Rondônia, no aspecto remuneração, em 2018, a média salarial oferecida aos trabalhadores desses dois setores (pecuária e abate) foi de $\mathrm{R} \$ 1.663,73$ (abaixo da média brasileira do setor, de $\mathrm{R} \$ 1.709,37)$. Se elencados em um ranking, os cinco setores que melhor remuneraram em 2018 no estado foram: 1) Serviços industriais de utilidade pública: R\$7.034,14; 2) Administração Pública: R\$ 3.421,22; 3) Serviços: $\mathrm{R} \$ 2.226,11$; 4) Extrativismo mineral: $\mathrm{R} \$ 2.049,50$; e 5) Construção Civil: R\$1.840,90 (RAIS, 2018).

Tabela 4 - Participação dos setores de criação e abate nos vínculos de emprego (2018)

\begin{tabular}{l|c|c|c|c}
\hline $\begin{array}{c}\text { Microrregiões } \\
\text { Rondênia }\end{array}$ & $\begin{array}{c}\text { Vínculos de } \\
\text { emprego } \\
\text { pelos setores } \\
\text { pecuária e } \\
\text { abate }\end{array}$ & $\begin{array}{c}\text { Total de } \\
\text { empregos } \\
\text { gerados }\end{array}$ & $\begin{array}{c}\text { Participação dos } \\
\text { setores pecuária e } \\
\text { abate nos vínculos } \\
\text { totais de emprego }\end{array}$ & $\begin{array}{c}\text { Média salarial } \\
\text { paga pelos } \\
\text { setores pecuária } \\
\text { e abate }\end{array}$ \\
\hline Alvorada D'Oeste $^{7}$ & 1.342 & 7.631 & $17,59 \%$ & $1.688,76$ \\
\hline Ariquemes $^{8}$ & 1.621 & 25.681 & $6,31 \%$ & $1.524,90$ \\
\hline Cacoal $^{9}$ & 4.725 & 40.504 & $11,67 \%$ & $1.617,73$ \\
\hline Colorado D'Oeste $^{10}$ & 988 & 7.268 & $13,59 \%$ & $1.673,04$ \\
\hline Guajará Mirim $^{11}$ & 389 & 6.454 & $6,03 \%$ & $1.417,99$ \\
\hline Ji-Paraná $^{12}$ & 5.447 & 51.521 & $10,57 \%$ & $1.657,67$ \\
\hline Porto Velho $^{13}$ & 1.832 & 172.405 & $1,06 \%$ & $1.615,83$ \\
\hline Vilhena $^{14}$ & 5.550 & 33.671 & $16,48 \%$ & $1.774,73$ \\
\hline RONDÔNIA & $\mathbf{2 1 . 8 9 4}$ & $\mathbf{3 4 5 . 1 3 5}$ & $\mathbf{6 , 3 4 \%}$ & $\mathbf{1 . 6 6 3 , 7 3}$ \\
\hline BRASIL & $\mathbf{1 . 0 0 3 . 3 9 0}$ & $\mathbf{4 6 . 6 3 1 . 1 1 5}$ & $\mathbf{2 , 1 5 \%}$ & $\mathbf{1 . 7 0 9 , 3 7}$ \\
\hline
\end{tabular}

Fonte: dados sistematizados pelos autores com base em RAIS (2018).

preparação de produtos de carne e de conservas de carne e de subprodutos quando integrada ao abate. A obtenção e tratamento de subprodutos do abate como: couros e peles sem curtir, lãs de matadouro, dentes, ossos, produção de óleos e gorduras comestíveis de origem animal, produção de couros e peles.

6 Divisão de microrregiões em Rondônia feita pela Relação Anual de Informações Sociais (RAIS).

7 Nova Brasilândia D’Oeste, São Miguel do Guaporé, Alvorada D’Oeste e Seringueiras.

8 Ariquemes, Machadinho D’Oeste, Rio Crespo, Alto Paraiso, Cacaulândia, Monte Negro e Vale do Anari.

9 Alta Floresta D'Oeste, Cacoal, Espigão D'Oeste, Rolim de Moura, Santa Luzia D'Oeste, Alto Alegre dos Parecis e Novo Horizonte D'Oeste.

10 Cabixi, Cerejeiras, Colorado D'Oeste, Corumbiara e Pimenteiras D'Oeste.

11 Costa Marques, Guajará-Mirim e São Francisco do Guaporé.

12 Jaru, Ji-Paraná, Ouro Preto D’Oeste, Presidente Médici, Governador Jorge Teixeira, Mirante da Serra, Nova União, Teixeirópolis, Theobroma, Urupá e Vale do Paraiso.

13 Porto Velho, Nova Mamoré, Buritis, Campo Novo de Rondônia, Candeias do Jamari, Cujubim e Itapuã D'Oeste.

14 Pimenta Bueno, Vilhena, Chupinguaia, Parecis, Primavera de Rondônia e São Felipe D’Oeste. 
Contudo, ainda no que se refere à geração de empregos, algumas observações são necessárias. É evidente que existe uma proporção de empregos ligados ao setor de pecuária que são informais e não constam na RAIS/ME. Estes não foram considerados devido à imprecisão de sua mensuração. Este é um fenômeno que ocorre em todos os setores econômicos, em maior ou menor medida.

Embora o objetivo desta análise esteja pautado no quantitativo de empregos (diretos) vinculados às atividades de criação e abate de bovinos, também é importante citar a proporção existente de empregos (indiretos) que estão vinculados a outras atividades que são necessárias para a pecuária se desenvolver, como a construção civil, o comércio de produtos agropecuários e implementos agrícolas, as indústrias lácteas etc. Como a RAIS é estruturada por segmentos econômicos diferentes, não foi possível desagregar subcategorias para um detalhamento da composição dos empregos ligados a esses setores.

Porém, mesmo com o fato de existir uma proporção de empregos indiretos ligados a setores próximos ao setor industrial pecuário, ainda assim se justifica afirmar que se comparados os altos investimentos financeiros e de infraestrutura, que são necessários para o desenvolvimento da indústria pecuária em Rondônia, estes não impactam, proporcionalmente da mesma forma, na geração direta de empregos. A renda gerada por esta atividade industrial, por seu turno, está concentrada principalmente entre os proprietários do latifúndio e entre os proprietários dos setores frigoríficos (LIMA, 2019).

\section{A INDÚSTRIA DO ABATE EM RONDÔNIA COMO REGIÃO DE ESPECISMO INTENSIVO}

A problemática ambiental e a relação com a natureza têm provocado estudos no campo da ética ambiental e da ética socioambiental ${ }^{15}$ a respeito dos processos de desenvolvimento que envolvem relações com a ética animal (FLORIT; GRAVA, 2016). A discussão sobre a categoria de especismo pode, de alguma maneira, contribuir na reflexão sobre os impactos existentes entre a atividade empresarial da indústria da carne e os interesses de existência dos seres sencientes não humanos ${ }^{16}$.

15 A ética ambiental é o campo de reflexão sobre os fundamentos éticos das nossas ações em relação à natureza e aos seres não humanos. É a especialidade da ética que atende a questões como: justifica-se uma atividade que criará empregos, mas provocará a extinção de espécies ou provoca a morte de animais? (FLORIT, 2016.). Já a ética socioambiental seria o campo de reflexão que faz interface entre a ética ambiental e os estudos sociais das iniquidades ambientais (FLORIT, 2018; FLORIT; SAMPAIO; PHILIPPI JUNIOR, 2019; MARZOCHI, 2017).

16 Seres sencientes são aqueles que têm capacidade de sentir sofrimento e outras sensações. Isto implica que eles têm também apreço pela sua própria vida e uma tendência espontânea a 
O termo "especismo" foi proposto pelo psicólogo britânico Richard Ryder ${ }^{17}$ em 1970, e está presente quando expressado no uso de peças de vestuário com matérias-primas provenientes de animais, na realização de operações ou estudos em animais vivos para o ensino ou observação de determinados fenômenos, bem como no uso de animais em práticas "esportivas" ou de "diversão", a exemplo dos jardins zoológicos (BRÜGGER, 2009).

No entanto, o problema do "especismo" é resultado de um longo processo de construção social entre o homem, a natureza e os animais (FLORIT; GRAVA, 2016). A questão do especismo é uma discussão derivada da ética ambiental, que tem entre seus expoentes teóricos o filósofo contemporâneo Peter Singer. O objetivo da reflexão sobre especismo, segundo Singer (2004), é estabelecer consideração moral por parte das pessoas a todas as categorias de seres não humanos que possuam a capacidade de responder aos diversos estímulos físicos e emocionais, principalmente a capacidade de sentir dor e sofrimento.

Embora já existam leis e regulamentações que proíbam algumas ações que perpetuam práticas especistas, para Brügger (2009) esses impedimentos normativos não são suficientes para contribuir com a visão de parte da sociedade que defende a ética e os direitos dos animais, a exemplo do fim da exploração como alimento ou como cobaias.

No contexto alimentar da indústria da carne, Singer (2004) afirma ser evidente a necessidade de se pensar alternativas que no mínimo diminuam o sofrimento dos animais ${ }^{18}$. Por outro lado, a categoria de especismo e a reflexão sobre padrões morais e éticos podem auxiliar em um exame crítico desses padrões de desenvolvimento (FLORIT; GRAVA, 2016).

No que se refere à indústria da carne em Rondônia, a discussão sobre o bem-estar animal pode gerar consequências contraditórias entre os grandes

buscar satisfação através daquilo que lhes traz bem-estar com base no seu senso de identidade psíquica ou mental. Nas palavras de Peter Singer, um filósofo importante na discussão animal, mas que não se encontra entre os mais radicais, "seres sencientes são aqueles que possuem um sistema nervoso que os habilitam sentir prazer e dor ao ponto de apresentar preferências para afugentar sensações ameaçadoras e buscar as satisfatórias à sua natureza. A senciência do animal favorece a sobrevivência de sua espécie” (SINGER, 2004, p. 18).

17 Richard Hood Jack Dudley Ryder é um psicólogo britânico que despertou a atenção ao se posicionar contra os testes com animais. Após desenvolver estudos com pesquisa animal, tornou-se um dos pioneiros no movimento de libertação animal.

18 Note-se que, embora estas discussões por vezes sejam vistas como "radicais", a proposta de Singer (2004) sugere um critério conservador, autocontido por dizer assim, para definir a fronteira da consideração moral. Singer não propõe uma ética biocêntrica que tivesse qualquer forma de vida como critério de consideração moral, posição pela qual é alvo de críticas já não pela ousadia das suas posições, mas, pelo contrário, pelos limites restritos dela (FELIPE, 2003, 2009; FLORIT, 2011). 
centros consumidores de carne (escala global) e as regiões de bovinocultura (escala regional). Para Florit e Grava (2016), a consequência dessa relação favorece ainda mais a condição para o estímulo à exploração industrial de animais em determinadas regiões brasileiras. Este fato que ocorre em diversas regiões do país é denominado pelos autores de Regiões de Especismo Intensivo (REI'S).

Nas regiões caracterizadas como REI'S, a legitimação da atividade econômica da indústria da carne se fundamenta socialmente como uma "vocação regional", ou seja, quando há um predomínio de uma atividade econômica em detrimento de outras, e desta forma, essa região pode ser considerada importante apenas por possuir uma suposta "vocação" (FLORIT; GRAVA, 2016; SBARDELATI, 2015).

A partir dessas "vocações", como fora afirmado acima, seus agentes produtivos tendem a desconsiderar outras possibilidades de atividade econômica no território. A atividade frigorífica existente nas REI'S se baseia no produtivismo industrial de "linhas de desmontagem animal", que, no caso dos bovinos, inicia após o abate (GRAVA 2019; SILVEIRA, 1999).

Em termos proporcionais, em muitas regiões brasileiras a quantidade de bovinos abatidos pode ser equiparada ou superada à quantidade populacional daquela região, fato que foi investigado e denominado por Florit e Grava (2016), em um estudo realizado em Santa Catarina, de índice de abate per capita.

Para os autores, o índice de abate per capita aponta a densidade de animais abatidos em um território, e os compara em relação ao tamanho populacional da mesma região. Esse índice se diferencia dos cálculos que expressam o peso total das carcaças, o que não revela a quantidade dos abates. Assim, o índice de abate per capita de um território pode ser considerado como um indicador de especismo do padrão de desenvolvimento predominante naquele território. Com base nas informações do Sistema IBGE de Recuperação Automática (SIDRA), foi levantado o índice de abate per capita em Rondônia e nos demais estados da região Norte no ano de 2019, conforme sistematizado na Tabela 5: 
Tabela 5 - Abate de bovinos e bubalinos no Brasil, na Região Norte e em Rondônia (2019)

\begin{tabular}{l|c|c|c|c}
\hline & $\begin{array}{c}\text { Animais } \\
\text { abatidos em } \\
\mathbf{2 0 1 9}\end{array}$ & $\begin{array}{c}\text { Total da } \\
\text { população }\end{array}$ & $\begin{array}{c}\mathbf{\%} \\
\text { Populacional }\end{array}$ & $\begin{array}{c}\text { Abate } \\
\text { per capita }\end{array}$ \\
\hline BRASIL & $\mathbf{3 2 . 4 3 6 . 4 5 1}$ & $\mathbf{1 9 0 . 7 5 5 . 7 9 9}$ & $\mathbf{1 0 0 \%}$ & $\mathbf{0 , 1 7}$ \\
\hline REGIÃO NORTE & $\mathbf{6 . 5 7 9 . 0 8 8}$ & $\mathbf{1 5 . 8 6 4 . 4 5 4}$ & $\mathbf{8 , 3 2 \%}$ & $\mathbf{0 , 4 1}$ \\
\hline ACRE & 416.498 & 733.559 & $0,38 \%$ & 0,57 \\
\hline AMAPÁ & -- & 669.526 & $0,35 \%$ & -- \\
\hline AMAZONAS & 247.259 & 3.483 .985 & $1,83 \%$ & 0,07 \\
\hline PARÁ & 2.407 .912 & 7.581 .051 & $3,97 \%$ & 0,32 \\
\hline RORAIMA & 82.553 & 450.479 & $0,24 \%$ & 0,18 \\
\hline RONDÔNIA & 2.392 .309 & 1.562 .409 & $0,82 \%$ & 1,53 \\
\hline TOCANTINS & 1.032 .557 & 1.383 .445 & $0,73 \%$ & 0,75 \\
\hline
\end{tabular}

Fonte: dados sistematizados pelos autores com base em IBGE (2010, 2019b).

Observa-se que de todos os estados da região Norte, apenas Rondônia apresenta um indicador de abate per capita mais expressivo. A análise da relação desse indicador com o padrão de desenvolvimento predominante em Rondônia envolve características da demografia do estado e do panorama regional das REI'S no abate de bovinos e bubalinos. São eles:

1) Representatividade populacional e de abate de bovinos:

A representatividade populacional na região Norte em relação ao total da população brasileira é de apenas 8,32\% (IBGE, 2010). Contudo, em termos de animais abatidos em 2019, a região Norte representou uma expressiva fatia de $20 \%$ do total do abate brasileiro de bovinos. A população de Rondônia representa $9,85 \%$ da população da região Norte, e apenas $0,82 \%$ da população brasileira. Porém, quando se trata do abate de bovinos e bubalinos, a proporção de Rondônia cresce para 36,36\% em relação ao total de abates na região Norte, e $7,38 \%$ em relação ao Brasil.

2) Panorama regional de indicador de especismo:

O indicador de especismo evidencia as regiões brasileiras cuja "vocação" regional está voltada na especialização de atividades que se apoiam na indústria pecuária e são legitimadas ao ponto de serem consideradas como padrão econômico predominante de desenvolvimento no território (FLORIT; GRAVA, 2016). Dos sete estados da região Norte do Brasil, apenas Rondônia possui esse indicador de especismo (ao abate per capita) ultrapassando um ponto e meio 
percentual $(1,53)$ (Tabela 5). Isto significa que a quantidade de animais abatidos excede o tamanho da população em mais de cinquenta por cento.

É importante salientar que este indicador de especismo inicialmente problematizou os padrões de desenvolvimento econômico amparados na indústria e no abate de bovinos, suínos e frangos em Santa Catarina. Diferentemente dos frangos e suínos, o ciclo produtivo dos bovinos possui características diferentes. O período de produção é menor, a quantidade produzida é maior e a criação exige grande área territorial de pastagens (EMBRAPA, 2012).

Em Rondônia, embora a população seja proporcionalmente menor, se comparado à Santa Catarina, ou aos maiores estados do Norte brasileiro Amazonas e Pará -, a quantidade de animais abatidos em Rondônia praticamente se equipara à quantidade de abates do Pará, ao ponto do estado ser considerado o segundo na região Norte com o maior número de abates em 2019 e o primeiro no índice per capita de abates $(1,53)$. Esta relação entre abates e população num território representa um dos principais atributos que caracterizam uma região como um padrão de desenvolvimento de especismo intensivo (REI'S).

\section{CONSIDERAÇÕES FINAIS}

O enfoque que a literatura faz sobre o neoextrativismo está, geralmente, voltado aos contextos da indústria da mineração e agrícola. Este artigo propõe ampliar a concepção do neoextrativismo também para a atividade pecuária em Rondônia, principalmente nos últimos quarenta anos a partir dos ciclos do agronegócio e das políticas de subsídios fiscais e concessão de terras que foram direcionadas para incentivar a migração populacional para a Amazônia brasileira.

Em Rondônia, o debate do desenvolvimento a partir da concepção do neoextrativismo justifica a importância da reflexão normativa em torno dos padrões de desenvolvimento, que são decorrentes de fatores condicionados pelas relações de poder, e se consolidam como um modelo predominante de desenvolvimento no território.

No caso da indústria da carne, é possível afirmar que a atividade em Rondônia integra um processo econômico internacional ligado ao agronegócio, que impacta na formulação de políticas de desenvolvimento concentradoras de recurso, com baixa remuneração e pouca geração de empregos diretos.

O agronegócio em Rondônia é financiado por grandes empresas do capital globalizado, e as relações entre o campo e a cidade se tornaram subordinadas aos interesses do mercado internacional. A indústria da carne apresenta características similares ao modelo econômico neoextrativista, pois concentra altos investimentos 
em infraestrutura (física e tecnológica), abarca as principais políticas institucionais para seu fomento e desenvolvimento, e a riqueza econômica gerada pela atividade pecuária fica concentrada entre os proprietários de terras e os setores agroindustriais como a JBS-Friboi e Marfrig Global Foods.

As externalidades ambientais negativas são outra característica das atividades que integram o modelo econômico neoextrativista. Em Rondônia, o avanço da fronteira agrícola e pecuária também contribuiu com a degradação ambiental, principalmente com o desmatamento para a formação de pastagens. O rebanho bovino no Brasil cresceu 26,50\% em 19 anos (2000 a 2019). Na região Norte, o crescimento correspondeu a 106,00\% no mesmo período. A pecuária rondoniense em 2019 alcançou 14.355.307 milhões de cabeças, uma expansão de 153,00\% do rebanho em duas décadas (2000-2019). Sua produção em 2019 correspondeu a 28,38\%, do total da região Norte, e 6,64\% do total da pecuária nacional.

Em termos populacionais, a representação de Rondônia em relação à população brasileira é de apenas 0,82\% (IBGE, 2010). Porém, quando se trata do quantitativo de bovinos abatidos no estado em 2019, a representação de Rondônia cresce para 7,38\% em relação ao total de abates no Brasil e 36,36\% em relação ao total de abates na região Norte.

A rotina de exploração da indústria pecuária em Rondônia nas últimas décadas é o argumento utilizado pelos atores econômicos envolvidos para legitimar uma suposta "vocação regional" do estado para o agronegócio. Em termos socioeconômicos de emprego e renda, em 2018 os setores que compreendem as atividades de criação e abate de bovinos responderam juntos por apenas 6,34\% do total de empregos (diretos) gerados. A média salarial oferecida aos trabalhadores desses dois setores foi de $\mathrm{R} \$ 1.663,73$ (abaixo da média brasileira do setor, de $\mathrm{R} \$ 1.709,37)$.

Desta forma, fica evidente que a maioria da renda gerada pela indústria da carne está concentrada principalmente entre os proprietários dos estabelecimentos rurais e o capital industrial da carne, que se consolida de forma hegemônica a partir da concepção do neoextrativismo. Essas relações de poder político e econômico manifestaram interesses pela apropriação do direito de exploração dos recursos naturais por companhias multinacionais e pelo latifúndio, o que historicamente produziu conflitos socioambientais graves em Rondônia.

Por fim, neste artigo, o estudo do neoextrativismo fundamentou a importância da reflexão normativa em torno dos padrões de desenvolvimento, que são, muitas vezes, decorrentes de fatores econômicos condicionados pelas relações de poder e, desta forma, se consolidam como padrão predominante de desenvolvimento ao ponto de produzir grandes externalidades ambientais 
negativas e alta concentração de renda. Complementa-se a isso o fato que os setores que integram o agronegócio em Rondônia, que são predominantemente apoiados por políticas públicas e privadas, não são os setores que mais empregam, tampouco os que melhor remuneram.

\section{REFERÊNCIAS}

ACOSTA, A. Extrativismo e neoextrativismo: duas faces da mesma maldição. In: DILGER, G.; LANG, M.; PEREIRA FILHO, J. (org.). Descolonizar o imaginário: debates sobre pós-extrativismo e alternativas ao desenvolvimento. São Paulo: Fundação Rosa Luxemburgo, 2016. p. 46-85.

\section{ALTVATER, E. Der Preis des Wohistandes oder Umweltplunderung und} neue Welt (in) ordnung. Munster: Westfalisches Dampfboot, 1992.

BARTON, J. R. Eco-dependency in Latin America. Singapore Journal of Tropical Geography, Singapore, v. 27, n. 2, p. 134-149, 2006.

BRÜGGER, P. Nós e os outros animais: especismo, veganismo e educação ambiental. Linhas Críticas, Brasília, DF, v. 15, n. 29, p. 197-214, 2009. Disponível em: http://www.redalyc.org/html/1935/193514388002/. Acesso em: 23 abr. 2018.

COSTA SILVA, R. G. A regionalização do agronegócio da soja em Rondônia. GeoUSP: espaço e tempo (online), São Paulo, v. 18, n. 2, p. 298312, 2014. Disponível em: https://www.revistas.usp.br/geousp/article/ view/84534/87447. Acesso em: 05 maio 2018.

COSTA SILVA, R. G.; CONCEIÇÃO, F. S. Agronegócio e campesinato na Amazônia brasileira: transformações geográficas em duas regiões nos estados de Rondônia e Pará. GEOgraphia, Niterói, v. 19, n. 41, p. 67-85, 2017. Disponível em: http://www.geographia.uff.br/index.php/geographia/article/ view/1008/743. Acesso em: 22 jul. 2018.

EMBRAPA. Idades de abate e seus respectivos pesos. Embrapa, Brasília, DF, 2012. Disponível em: https://cloud.cnpgc.embrapa.br/sac/2012/10/16/ prezados-senhores-busquei-no-site-a-embrapa-e-nao-obtive-exito-1-onde-possoobter-o-peso-medio-de-um-novilho-2-onde-posso-obter-o-peso-medio-de-um-boi-com-45-meses-3-um-novilho-e-considerado-no/. Acesso em: 20 nov. 2018. FELIPE, S. T. Por uma questão de princípios: alcance e limites da ética de Peter Singer em defesa dos animais. Florianópolis: Boiteux, 2003. 
FELIPE, S. T. Antropocentrismo, sencientismo e biocentrismo: perspectivas éticas abolicionistas, bem-estaristas e conservadoras e o estatuto de animais não humanos. Páginas de Filosofia, São Bernardo do Campo, v. 1, n. 1, p. 1-30, jan./jul. 2009.

FERNANDES, B. M. (org.). Campesinato e agronegócio na América Latina: a questão agrária atual. São Paulo: Expressão Popular, 2008.

FLORIT, L. F; Natureza, especismo e vocações ambientais: dilemas éticos e políticos para o desenvolvimento territorial sustentável. In: ENCONTRO NACIONAL DA ANPUR, 14., 2011, Rio de Janeiro. Anais [...]. Rio de Janeiro: ANPUR, 2011. p. 1-20. Disponível em: https:// anais.anpur.org.br/index.php/ anaisenanpur/article/view/902. Acesso em: 29 out. 2021.

FLORIT, L. F. Conflitos ambientais, desenvolvimento no território e conflitos de valoração: considerações para uma ética ambiental com equidade social. Desenvolvimento e Meio Ambiente, Curitiba, v. 36, p. 255-271, 2016. Disponível em: https://revistas.ufpr.br/made/article/view/41624 Acesso em: 14 nov. 2021.

FLORIT, L. F. Ética ambiental ocidental e os direitos da natureza. Contribuições e limites para uma ética socioambiental na América Latina. Pensamiento Actual, Alajuela, v. 17, n. 28, p. 121-136, 2017. Disponível em: https:/ / dialnet.unirioja.es / servlet/articulo?codigo $=6053590$ Acesso em: 14 nov. 2021.

FLORIT, L. F; GRAVA, D. S. Ética ambiental e desenvolvimento territorial sustentável: uma análise com base na categoria de especismo. Ambiente \& Sociedade, São Paulo, v. 19, n. 4, p. 39-58, 2016. Disponível em: https://www.scielo.br/j/asoc/a/GwW9VnxDpCP8jg4y7yQmqkg /?lang=pt. Acesso em: 29 out. 2021.

FLORIT, L. F.; SAMPAIO, C. A.; PHILIPPI JUNIOR, A. Os desafios da ética socioambiental. In: FLORIT, L. F; SAMPAIO, C. A.; PHILIPPI JUNIOR, A. (Ed.). Ética socioambiental. Barueri: Manole, 2019. p. 03-15.

FURTADO, C. Formação econômica do Brasil. 32. ed. São Paulo: Companhia Editora Nacional, 2005.

GOULET, D. Development indicators: a research problem, a policy problem. The Journal of Socio-Economics, [s. l.], v. 21, n. 3, p. 245-260, 1992. 
GRAVA, D. S. Vocações regionais, território e justiça socioecológica. In: FLORIT, L. F.; SAMPAIO, C. A.; PHILIPPI JUNIOR, A. (Ed.). Ética socioambiental. Barueri: Manole, 2019. p. 231-260.

GUDYNAS, E. Diez tesis urgentes sobre el nuevo extractivismo: contexto y demandas bajo el progressismo sudamericano actual. In: SCHULDT, J. et al. (coord..). Extractivismo, política y sociedade. Quito: Centro Andino de Acción Popular e Centro Latino Americano de Ecologia Social, 2009. p. 187-225. GUDYNAS, E. Estado compensador y nuevos extractivismos. Las ambivalencias del progresismo sudamericano. Nueva Sociedad, Buenos Aires, v. 237, p. 128-146. 2012a. Disponível em: https://nuso.org/articulo/estadocompensador-y-nuevos-extractivismos-las-ambivalencias-del-progresismosudamericano/. Acesso em: 10 out. 2018.

GUDYNAS, E. O novo extrativismo progressista na América do Sul: teses sobre um velho problema sob novas expressões. In: LÉNA, P.; NASCIMENTO, E. P. Enfrentando os limites do crescimento: sustentabilidade, decrescimento e prosperidade. Rio de Janeiro: Garamond: IRD, 2012b. p. 303-318.

HEIN, W. Fachubersicht: Zur Theorie der Unterentwicklung und ihrer Uberwindung. Peripherie, [s. l.], v. 2, n. 5-6, p. 64-91, 1981.

HEINRICH BOLL FOUNDATION. Atlas da carne: fatos e números sobre os animais que comemos. Rio de Janeiro: Heinrich Böll Foundation, 2016. 68 p. Disponível em: http://actbr.org.br/uploads/arquivo/1123_atlasdacarne.pdf. Acesso em: 22 nov. 2018.

IBGE. Censo Agropecuário 2006. IBGE, Rio de Janeiro, 2006. Disponível em: http://www.ibge.gov.br/home/estatistica/economia/agropecuaria/censoagro/. Acesso em: 25 jan. 2017.

IBGE. Censo demográfico 2010. IBGE, Rio de Janeiro, 2010. Disponível em: http://censo2010.ibge.gov.br/. Acesso em: 25 jan. 2017.

IBGE. Sistema IBGE de recuperação automática: efetivo dos rebanhos, por tipo de rebanho 2018-2019. IBGE, Rio de Janeiro, 2019a. Disponível em: https://sidra.ibge.gov.br/tabela/1092\#resultado Acesso em: 20 mar. 2020.

IBGE. Sistema IBGE de recuperação automática: animais abatidos (cabeças) 2019. IBGE, Rio de Janeiro, 2019b. Disponível em: https:/ /sidra.ibge.gov.br/ tabela/1092\#resultado. Acesso em: 20 mar. 2020. 
IDARON. Informe semestral de campo referente a 47 etapa de vacinação contra febre aftosa/2019. IDARON, Porto Velho, 2019. Disponível em: http://www.idaron.ro.gov.br/wp-content/uploads/2020/01/ Vacina\%C3\%A7\%C3\%A3o-do-Rebanho-Geral.pdf. Acesso em: 04 abr. 2020. KAMPEL, S.; CÂMARA, G.; MONTEIRO, A. M. V. Análise espacial do processo de urbanização da Amazônia. São José dos Campos: Instituto Nacional de Pesquisas Espaciais, 2001. Disponível em: http://www.dpi.inpe. br/geopro/modelagem/relatorio_urbanizacao_amazonia.pdf. Acesso em: 25 maio 2018.

LANG, M. Alternativas ao Desenvolvimento. In: DILGER, G.; LANG, M.; PEREIRA FILHO, J. (org.). Descolonizar o imaginário: debates sobre pósextrativismo e alternativas ao desenvolvimento. São Paulo: Fundação Rosa Luxemburgo, 2016. p. 24-44.

LIMA, C. C. Agroextrativismo e Neoextrativismo na Amazônia: um estudo sobre comunidades extrativistas no contexto do padrão de desenvolvimento em Rondônia. 2019. Tese (Doutorado em Desenvolvimento Regional) - Programa de Pós-Graduação em Desenvolvimento Regional, Fundação Universidade Regional de Blumenau, Blumenau, 2019.

MARTINI, D. Z.; MOREIRA, M. A.; DALLA-NORA, E. Emprego de Geotecnologias para identificar áreas para expansão agrícola de soja no Estado de Rondônia. In: SIMPÓSIO BRASILEIRO DE SENSORIAMENTO REMOTO, 17., 2015, João Pessoa. Anais [...]. João Pessoa: INPE, 2015. p.1455-1462. Disponível em: http://www.dsr.inpe.br/sbsr2015/files/p0271. pdf. Acesso em: 28 ago. 2018.

MARZOCHI, S. F. Ética ambiental no Brasil: história, campo de estudos e militância: entrevista com Luciano Félix Florit. Contemporânea-Revista de Sociologia da UFSCar, São Carlos, v. 8, n. 1, p. 343-343, 2018. Disponível em: https://www.contemporanea.ufscar.br/index.php/contemporanea/article/ view/668 Acesso em: 14 nov. 2021.

MATHUR, G. B. The current impasse in development thinking: the metaphysics of power. Alternatives, [s. l.], v. 14, n. 4, p. 463-479, 1989.

MELLO, N. A. Políticas territoriais na Amazônia. São Paulo: Annablume, 2006. 412 p. 
MILANEZ, B.; SANTOS, R. S. P. Neoextrativismo no Brasil? Uma análise da proposta do novo marco legal da mineração. R. Pós Ci. Soc., São Luís, v. 10, n. 19, p. 119-148, jan./jun. 2013. Disponível em: http:/ /www. periodicoseletronicos.ufma.br/index.php/rpcsoc/article/view/1940. Acesso em: 02 fev. 2018.

OLIVEIRA, O. F. Território e cidadania em Rondônia: estudo das políticas de desenvolvimento rural sustentável nos territórios Central e Madeira Mamoré. 2012. Tese (Doutorado em Desenvolvimento Regional) - Programa de PósGraduação em Desenvolvimento Regional, Universidade de Santa Cruz do Sul, Santa Cruz do Sul, 2012.

PAULA, E. A.; SILVA, S. S. Movimentos sociais na Amazônia brasileira: vinte anos sem Chico Mendes. Revista Nera, Presidente Prudente, n. 13, p. 102117, 2008. Disponível em: http:/ / revista.fct.unesp.br/index.php/nera/article/ view/1391/1373. Acesso em: 10 out. 2018.

PEET, R. Global capitalism: theories of societal development. London, UK: Routledge, 1991.

RAIS. Ministério da Economia. Relação Anual de Informações Sociais/RAIS 2018. RAIS, Brasília, DF, 2018. Disponível em: http://www.rais.gov.br/sitio/ download.jsf\#layouts. Acesso em: 12 mar. 2020.

\section{SBARDELATI, C. Vocação regional e identidade profissional na}

construção do território: o caso da consolidação da agroindústria da carne no município de Concórdia em Santa Catarina. 2015. Dissertação (Mestrado em Desenvolvimento Regional) - Programa de Pós-Graduação em Desenvolvimento Regional, Fundação Universidade Regional de Blumenau, Blumenau, 2015. Disponível em: http://www.bc.furb.br/docs/ DS/2015/358773_1_1.pdf. Acesso em: 08 ago. 2018.

SCHLESINGER, S. Onde pastar? O gado bovino no Brasil. Rio de Janeiro: FASE, 2010. Disponível em: http://fase.org.br/pt/acervo/biblioteca/ondepastar-o-gado-bovino-no--brasil/. Acesso em: 03 jul. 2019.

SCOTTO, G. Estados nacionais, conflitos ambientais e mineração na América Latina. Letras Verdes, Madrid, n. 14, p. 95-116, 2013. Disponível em: https:/ / dialnet.unirioja.es/servlet/articulo?codigo=5444026. Acesso em: 10 mar. 2018. SILVEIRA, D. D. Modelo para seleção de sistemas de tratamento de efluentes de indústrias de carnes. 1999. Tese (Doutorado em Engenharia de Produção) - Programa de Pós-Graduação em Engenharia de Produção, Universidade Federal de Santa Catarina, Florianópolis, 1999. 
SINGER, P. Libertação animal. Porto Alegre: Lugano, 2004.

SVAMPA, M. Extrativismo neodesenvolvimentista e movimentos sociais: um giro ecoterritorial rumo a novas alternativas? In: DILGER, G.; LANG, M.; PEREIRA FILHO, J. (org.). Descolonizar o imaginário: debates sobre pósextrativismo e alternativas ao desenvolvimento. São Paulo: Fundação Rosa Luxemburgo, 2016. p. 140-171.

TEIXEIRA, M. A. D.; FONSECA, D. R. História regional: Rondônia. Porto Velho: Rondoniana, 2001. 232 p.

THEIS, I. M. (org.). Desenvolvimento e território: questões teóricas, evidências empíricas. Santa Cruz do Sul: EDUNISC, 2008.

THEOFANIDES, S. The metamorphosis of development economics. Word Development, [s. l.], v. 16, n. 12, p. 1455-1463, 1988.

WEBER, Max. Ciência e política: duas vocações. Editora Cultrix, 2004.

ZEN, S.; BARIONI, L.G.; BONATO, D. B. B.; ALMEIDA, M. H. S.; RITTL, T. F. Pecuária de corte brasileira: impactos ambientais e emissões de gases efeito estufa (GEE). Sumário Executivo. Piracicaba: ESALQ/CEPEA, 2008. Disponível em: https://www.cepea.esalq.usp.br/br/documentos/texto/ pecuaria-de-corte-brasileira-impactos-ambientais-e-emissoes-de-gases-efeitoestufa-gee.aspx Acesso em: 10 fev. 2018. 